\title{
SELEKSI KARYAWAN KEUANGAN DI PT. BUMI HUTAN SEMESTA MENGGUNAKAN METODE AHP
}

\author{
Rezky Izzatul Yazidah Anwar \\ Fakultas Teknologi Informasi \\ Universitas Islam Kalimantan Muhammad Arsyad Al Banjari Banjarmasin \\ Email : rezky.izzatul@gmail.com
}

\begin{abstract}
ABSTRAK
Sumber daya manusia merupakan salah satu sumber daya yang paling penting bagi perusahaan. Salah satu aktifitas yang penting bagi perusahaan adalah proses penerimaan atau seleksi sumber daya manusia itu sendiri, yang sering disebut seleksi karyawan. Pada umumnya seleksi karyawan pada perusahaan swasta tidak terlalu memperhatikan detail syarat para calon karyawan, yang terpenting adalah kemampuannya dan syarat umum saja. Pada kenyataannya pengambilan keputusan secara efisien dan efektif pada saat melakukan seleksi terhadap sumber daya manusia bukanlah hal yang mudah, maka diperlukan suatu model pengambilan keputusan untuk membantu memecahkan masalah tersebut, sehingga tidak ada lagi penilaian subjektif terhadap calon karyawan dan dapat menempatkan karyawan sesuai dengan kemampuan dan bidang yang ditekuninya. Dalam hal ini AHP (Analytichal Hierarchy Process) digunakan sebagai metode untuk membantu menentukan kriteria-kriteria ideal yang akan digunakan pada saat proses seleksi, hingga mengurutkan berdasarkan skor tertinggi. Kriteria disusun dengan struktur hirarki, untuk memudahkan proses seleksi.
\end{abstract}

Kata Kunci : AHP, Seleksi Karyawan, Sumber Daya Manusia

\section{PENDAHULUAN}

Sistem seleksi penerimaan karyawan saat ini banyak dengan penilaian subjektif. Padahal tanpa disadari itu secara tidak langsung akan mempengaruhi kinerja perusahaan, karena kurangnya perhatian terhadap pengelolaan sumber daya manusianya. Seperti yang terjadi pada PT. Bumi Hutan Semesta yang terletak di Kalimantan Tengah. Perusahaan ini merupakan sebuah perusahaan yang bergerak dibidang perkebunan kelapa sawit. Sehingga kadang mempengaruhi kinerja perusahaan dan berdampak buruk pada perkembangan perusahaan, karena kurangnya kemampuan dalam menguasai bidang pekerjaan yang diberikan kepadanya.
Kriteria yang dibutuhkan perusahaan adalah dilihat dari ijazah terakhir minimal diploma 3, jurusan akuntansi, adanya pengalaman kerja minimal 2 tahun kerja, serta memiliki nilai test tertulis dan wawancara yang baik. Dan dari 35 pelamar hanya 1 orang yang dibutuhkan untuk bagian keuangan. Faktanya ada sekitar $29 \%$ ( persen ) atau 10 orang dari pelamar, yang memenuhi kriteria namun ditolak. Sedangkan, $3 \%$ ( persen ) atau 1 orang pelamar yang tidak memenuhi kriteria justru diterima.

Dalam penelitian kali ini menerapkan metode AHP karena AHP pada dasarnya, merupakan proses pengambilan keputusan untuk memilih suatu alternatif pilihan penilaian yang 
mirip. Maka disini akan dibangun sebuah sistem seleksi penerimaan karyawan bagian keuangan dengan penerapan metode AHP (Analytichal Hierachy Process) di PT. Bumi Hutan Semesta, agar membantu untuk memberikan hasil akurat penilaian sebagai pertimbangan para pengambil keputusan sehingga dapat memilih calon karyawan yang tepat untuk bagian keuangan dan mengubah sistem subjektif yang ada selama ini.

\section{RUMUSAN MASALAH}

Bagaimana menerapkan metode AHP (Analytichal Hierachy Process) pada seleksi penerimaan karyawan bagian

\section{METODE PENELITIAN}

\section{Metode Pengumpulan Data}

Data yang digunakan dalam penelitian ini berupa Data yang diambil secara langsung dari objek keuangan di PT. Bumi Hutan Semesta, dapat menjadi pertimbangan pengambilan keputusan.

\section{TARGET LUARAN DAN MANFAAT PENELITIAN}

Target luaran dari penelitian ini adalah menerapkan metode AHP dalam proses seleksi penerimaan karyawan bagian keuangan sehingga dapat meningkatkan kualitas karyawan baru yang akan bekerja di perusahaan. Sedangkan Manfaatnya adalah menghasilkan proses seleksi penerimaan karyawan bagian keuangan sesuai dengan kriteria yang ditentukan.

yaitu PT. Bumi Hutan Semesta dan data kriteriakriteria penilaian seleksi. Semua data tersebut akan menjadi variable yang akan dianalisa oleh metode.

Tabel 1. Kriteria Seleksi Karyawan

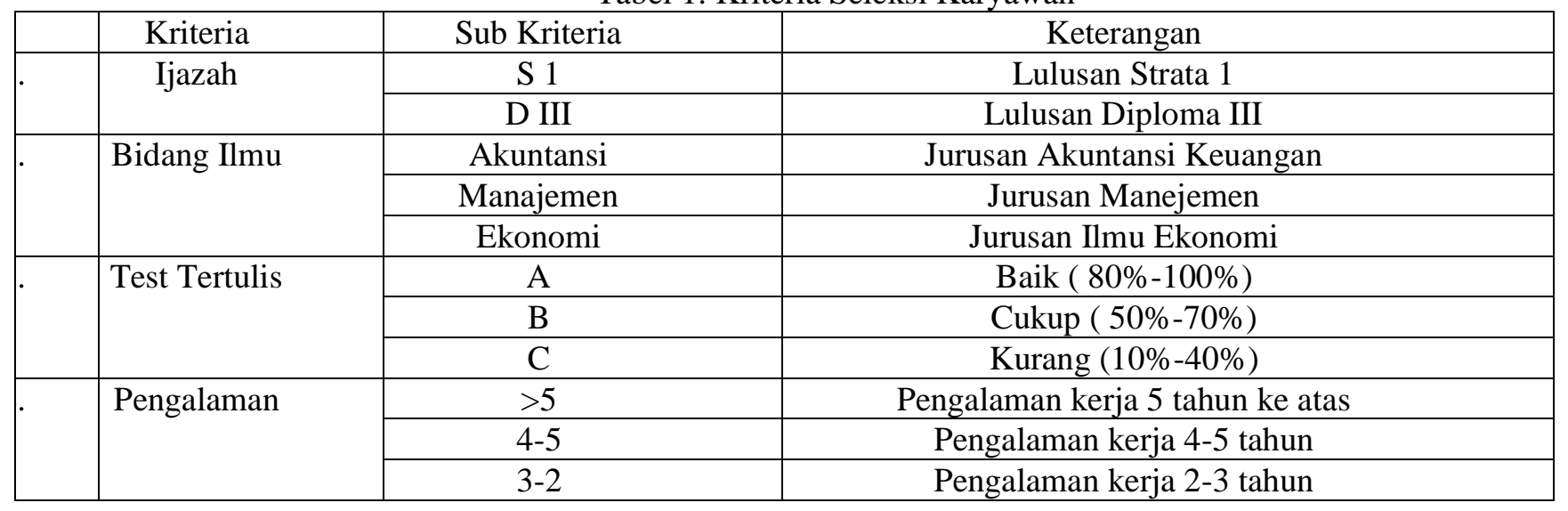

Tabel 2. Kriteria Seleksi Karyawan

\begin{tabular}{|c|c|c|c|c|c|c|c|c|}
\hline \multirow{2}{*}{ No Register } & \multicolumn{4}{|c|}{ Administrasi } & \multicolumn{3}{|c|}{ Test Wawancara } & \multirow[t]{2}{*}{ Hasi } \\
\hline & Ijazah & Bidang Ilmu & Lama Kerja & Test Tertulis & Sikap & $\begin{array}{c}\text { Kemampuan } \\
\text { Menjawab }\end{array}$ & $\begin{array}{r}\text { Pemakaian } \\
\text { Bahasa }\end{array}$ & \\
\hline 1703252 & S1 & Ekonomi & 2 tahun & $\mathrm{B}$ & Baik & Cukup & Baik & Ditolak \\
\hline 1703227 & D3 & Akuntansi & 2 tahun & $\mathrm{B}$ & Baik & Cukup & Cukup & Ditolak \\
\hline 1703046 & SMA & - & 2 tahun & B & - & - & - & Ditolak \\
\hline 1703220 & S1 & Manajemen & 3 tahun & $\mathrm{B}$ & Cukup & Baik & Baik & Ditolak \\
\hline 1703257 & SMA & - & 4 tahun & $\mathrm{A}$ & Baik & Kurang & Cukup & Ditolak \\
\hline 1703056 & S1 & Ekonomi & 3 tahun & B & Baik & Baik & Kurang & Ditolak \\
\hline 1703158 & S1 & Tek.Sipil & 1 tahun & A & Cukup & Kurang & Cukup & Ditolak \\
\hline
\end{tabular}




\begin{tabular}{|c|c|c|c|c|c|c|c|c|}
\hline 1703179 & S1 & Akuntasi & 2 tahun & A & Baik & Baik & Cukup & Ditolak \\
\hline 1703221 & SMA & - & 0 tahun & A & Baik & Cukup & Cukup & Diterima \\
\hline 1703275 & D3 & Tek.Kimia & 3 tahun & $\mathrm{C}$ & Baik & Kurang & Cukup & Ditolak \\
\hline 1703104 & D3 & Akuntansi & 3 tahun & B & Baik & Cukup & Cukup & Ditolak \\
\hline 1703071 & D3 & Pelayaran & 1 tahun & $\mathrm{C}$ & - & - & - & Ditolak \\
\hline 1703199 & S1 & Ekonomi & 2 tahun & B & Baik & Baik & Baik & Ditolak \\
\hline 1703221 & S1 & Pend. Bio. & 1 tahun & B & - & - & - & Ditolak \\
\hline 1703192 & SMA & - & 0 tahun & B & - & - & - & Ditolak \\
\hline 1703060 & SMA & - & 0 tahun & B & - & - & - & Ditolak \\
\hline 1703093 & SMA & - & 1 tahun & $\mathrm{C}$ & - & - & - & Ditolak \\
\hline 1703079 & SMA & - & 3 tahun & B & - & - & - & Ditolak \\
\hline 1703090 & SMA & - & 0 tahun & B & - & - & - & Ditolak \\
\hline 1703133 & SMA & - & 0 tahun & B & - & - & - & Ditolak \\
\hline 1703240 & D3 & Manajemen & 2 tahun & B & aik & Baik & Baik & Ditolak \\
\hline 1703050 & SMA & - & 0 tahun & $\mathrm{B}$ & - & - & - & Ditolak \\
\hline 1703057 & S1 & Pertanian & 1 tahun & B & ikup & Baik & Baik & Ditolak \\
\hline 1703055 & SMA & - & 3 tahun & B & - & - & - & Ditolak \\
\hline 1703218 & SMA & - & 0 tahun & A & aik & Baik & Kurang & Ditolak \\
\hline 1703211 & SMA & - & 5 tahun & B & - & - & - & Ditolak \\
\hline 1703145 & SMA & - & 0 tahun & $\mathrm{C}$ & - & - & - & Ditolak \\
\hline 1703290 & SMA & $\begin{array}{ll}- \\
-\end{array}$ & 0 tahun & $\mathrm{C}$ & - & - & - & Ditolak \\
\hline 1703187 & S1 & Manajemen & 2 tahun & B & aik & Baik & Baik & Ditolak \\
\hline 1703058 & SMA & - & 0 tahun & $\mathrm{C}$ & - & - & - & Ditolak \\
\hline 1703286 & SMA & - & 3 tahun & C & - & - & - & Ditolak \\
\hline 1703231 & S1 & Adm.Pend. & 1 tahun & A & aik & Baik & Cukup & Ditolak \\
\hline 1703058 & D3 & Akuntansi & 2 tahun & B & aik & Cukup & Baik & Ditolak \\
\hline 1703151 & SMA & - & 4 tahun & B & - & - & - & Ditolak \\
\hline 1703180 & SMA & - & 2 tahun & $\mathrm{C}$ & - & - & - & Ditolak \\
\hline
\end{tabular}

Keterangan : Nilai Rata-rata benar :

A $(80-100 \%)=$ Baik

B $(50-70 \%)=$ Cukup

C $(10-40 \%)=$ Kurang

Nilai wawancara :

$\mathrm{OK}=$ Nilai baik

TDK $=$ Nilai kurang

Dari kriteria yang ada diperusahaan adalah ijazah terakhir minimal diploma 3 akuntansi, adanya pengalaman kerja minimal 2 tahun, serta memiliki nilai test tertulis dan nilai wawancara yang baik. Dan yang terjadi dari rekap data di atas dapat dilihat bahwa telah terjadi subjektifitas dalam penilaian. Ada $29 \%$ (persen) atau 10 orang pelamar yang memenuhi kriteria namun tidak diterima. Sedangkan $3 \%$ (persen) atau 1 orang pelamar yang jelas tidak memenuhi kriteria perusahaan justru diterima. Dampak dari semua ini adalah hasil kinerja karyawan yang tidak maksimal sehingga mengganggu perkembangan perusahaan.

\section{Diagram Konteks}


Diagram konteks adalah diagram yang terdiri dari suatu proses dan menggambarkan ruang lingkup suatu sistem. Diagram konteks merupakan level tertinggi dari DFD yang menggambarkan seluruh input ke sistem atau output dari sistem. Diagram konteks berisi gambaran umum (secara garis besar) sistem yang akan dibuat. Dari admin yang memasukkan data calon karyawan ke aplikasi hingga laporan yang dihasilkan yang akan diserahkan kepada pengambil keputusan.

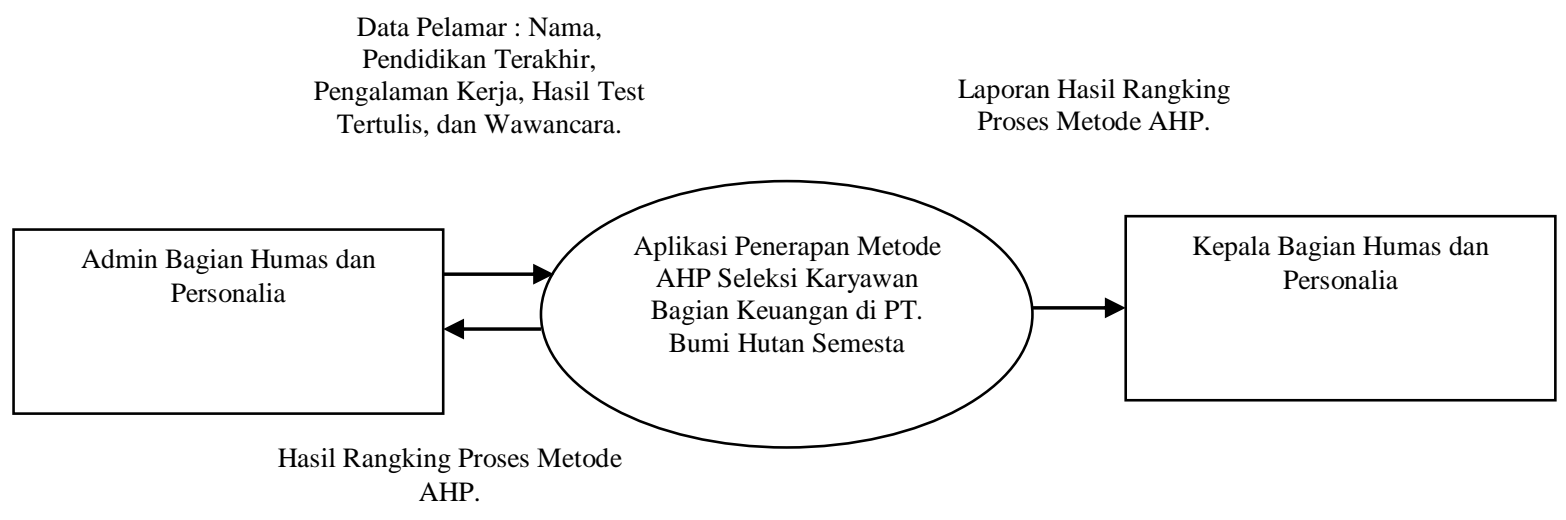

Gambar 1. Diagram Kontek Seleksi Atlet dengan AHP

HASIL DAN PEMBAHASAN

Hasil Penelitian

a. Penelitian dilakukan dengan menginput data kriteria karyawan diolah dengan metode AHP menghasilkan rangking dalam software Delphi.

b. Dari data yang telah dibuat, kemudian diolah user accepted untuk mengetahui kelayakan aplikasi yang di olah. Pengujian User Acceptance dilakukan pada penelitian ini agar mengetahui bahwa aplikasi yang telah dibuat ini layak digunakan atau justru memiliki banyak kekurangan. Pengujian

\section{Pembahasan}

a. Pengujian white box digunakan untuk mengetahui cara kerja suatu perangkat lunak secara internal. Pengujian dilakukan untuk menjamin operasi - operasi internal sesuai dengan spesifikasi yang telah ditetapkan dengan menggunakan struktur kendali dari
User Acceptance merupakan pengujian yang dilakukan secara objektif dimana aplikasi diuji dengan membuat kuesioner mengenai kepuasan user dengan kandungan point syarat user friendly.

c. Setelah itu maka akan dilakukan evalusi terhadap software melalui pengujian Pre test dan Post test untuk mengetahui seberapa pengaruhnya metode AHP terhadap perengkingan atlet bulu tangkis. Sehingga didapatkannya perengkingan dengan akurasi yang baik.

prosedur yang dirancang. Dalam hal ini, pengujian tidak dilakukan terhadap keseluruhan program tetapi hanya dilakukan pada sampel pengujian untuk seleksi karyawan.

b. Pengujian black box digunakan untuk menguji fungsi-fungsi khusus dari perangkat 
lunak yang dirancang. Pada teknik pengujian black box kebenaran perangkat luank yang diuji hanya dilihat berdasarkan keluaran yang dihasilkan dari data atau kondisi masukan yang diberikan untuk fungsi yang ada tanpa melihat bagaimana proses untuk mendapatkan keluaran tersebut. c. Aplikasi yang telah dibuat ini layak atau masih memiliki banyak kekurangan.

d. Pengujian User Acceptance ini menggunakan kuisioner yang diberikan kepada 5 responden berdasarkan model skala likert (lima pilihan jawaban)

Tabel 2. Data User Accepted

\begin{tabular}{|c|c|c|c|c|c|}
\hline $\mathbf{A}$ & Pertanyaan & TS & $\mathbf{C}$ & $\mathbf{S}$ & SS \\
\hline 1 & Apakah aplikasi efektif digunakan saat ini ? & 0 & 0 & 3 & 2 \\
\hline 2 & Apakah aplikasi ini berguna dan sesuai kebutuhan ? & 0 & 0 & 1 & 4 \\
\hline 3 & Apakah aplikasi ini mudah untuk dipelajari dan dipahami? & 0 & 0 & 4 & 1 \\
\hline 4 & Apakah aplikasi ini mudah digunakan? & 0 & 0 & 4 & 1 \\
\hline 5 & Apakah tampilan dari aplikasi ini menarik? & 0 & 1 & 3 & 1 \\
\hline 6 & Apakah laporan yang ditampilkan sudah sesuai dengan kebutuhan? & 0 & 0 & 2 & 3 \\
\hline
\end{tabular}

Didapat nilai Alpha Cronbach adalah 0,654 dengan jumlah pertanyaan 5 buah. Alpha Cronbach $=0,654$ terletak antara 0,60 hingga 0,80 sehingga tingkat reliabilitasnya reliable.

Dari semua hasil pengujian yang telah dilakukan dari pengujian validitas maupun reliabilitas menunjukkan bahwa pengujian User Acceptance ini telah menghasilkan data yang valid dengan tingkat reabilitasnya termasuk Reliabel.
Pre Test dan Post Test merupakan sebuah evaluasi yang diadakan untuk menguji konsep dan eksekusi yang direncanakan. Untuk mengetahui pengaruh dari penerapan AHP pada kasus penentuan prioritas seleksi karyawan, maka disajikan hasil prioritas atlet berdasarkan pada perhitungan Manual AHP dan perhitungan program AHP.

Tabel 4. Contoh data Perhitungan pretest dan posttest

\begin{tabular}{|c|c|c|c|c|c|c|c|c|c|c|}
\hline \multirow{2}{*}{$\begin{array}{l}\text { No } \\
\text { · }\end{array}$} & \multirow{2}{*}{ No Register } & \multicolumn{4}{|c|}{ Administrasi } & \multicolumn{3}{|c|}{ Test Wawancara } & \multirow[t]{2}{*}{ Hasil } & \multirow[t]{2}{*}{ Ket. } \\
\hline & & Ijazah & $\begin{array}{c}\text { Bidang } \\
\text { Ilmu }\end{array}$ & $\begin{array}{c}\text { Lama } \\
\text { Kerja }\end{array}$ & $\begin{array}{c}\text { Test } \\
\text { Tertulis }\end{array}$ & Sikap & $\begin{array}{c}\text { Kemampuan } \\
\text { Menjawab }\end{array}$ & $\begin{array}{c}\text { Pemakaian } \\
\text { Bahasa }\end{array}$ & & \\
\hline 1 & 1703252 & S1 & Ekonomi & 2 tahun & $\mathrm{B}$ & Baik & Cukup & Baik & Diterima & Sesuai \\
\hline 2 & 1703227 & D3 & Akuntansi & 2 tahun & B & Baik & Cukup & Cukup & Diterima & Sesuai \\
\hline 3 & 1703046 & SMA & - & 2 tahun & B & - & - & - & Ditolak & Sesuai \\
\hline 4 & 1703220 & S1 & Manajemen & 3 tahun & B & Cukup & Baik & Baik & Ditolak & $\begin{array}{l}\text { Tidak } \\
\text { Sesuai }\end{array}$ \\
\hline 5 & 1703257 & SMA & - & 4 tahun & A & Baik & Kurang & Cukup & Ditolak & Sesuai \\
\hline 6 & 1703056 & S1 & Ekonomi & 3 tahun & B & Baik & Baik & Kurang & Diterima & Sesuai \\
\hline 7 & 1703158 & S1 & Tek.Sipil & 1 tahun & A & Cukup & Kurang & Cukup & Ditolak & Sesuai \\
\hline 8 & 1703179 & S1 & Akuntasi & 2 tahun & A & Baik & Baik & Cukup & Diterima & Sesuai \\
\hline 9 & 1703221 & SMA & - & 0 tahun & A & Baik & Cukup & Cukup & Ditolak & Sesuai \\
\hline 10 & 1703275 & D3 & Tek.Kimia & 3 tahun & $\mathrm{C}$ & Baik & Kurang & Cukup & Diterima & Sesuai \\
\hline 11 & 1703104 & D3 & Akuntansi & 3 tahun & B & Baik & Cukup & Cukup & Ditolak & Sesuai \\
\hline 12 & 1703071 & D3 & Pelayaran & 1 tahun & $\mathrm{C}$ & - & - & - & Ditolak & Sesuai \\
\hline 13 & 1703199 & S1 & Ekonomi & 2 tahun & B & Baik & Baik & Baik & Diterima & Sesuai \\
\hline 14 & 1703221 & S1 & Pend. Bio. & 1 tahun & B & - & - & - & Ditolak & Sesuai \\
\hline
\end{tabular}




\begin{tabular}{|c|c|c|c|c|c|c|c|c|c|c|}
\hline 15 & 1703192 & SMA & - & 0 tahun & B & - & - & - & Ditolak & Sesuai \\
\hline 16 & 1703060 & SMA & - & 0 tahun & B & - & - & - & Ditolak & Sesuai \\
\hline 17 & 1703093 & SMA & - & 1 tahun & $\mathrm{C}$ & - & - & - & Ditolak & Sesuai \\
\hline 18 & 1703079 & SMA & - & 3 tahun & B & - & - & - & Ditolak & Sesuai \\
\hline 19 & 1703090 & SMA & - & 0 tahun & B & - & - & - & Ditolak & Sesuai \\
\hline 20 & 1703133 & SMA & - & 0 tahun & B & - & - & - & Ditolak & Sesuai \\
\hline 21 & 1703240 & D3 & Manajemen & 2 tahun & B & Baik & Baik & Baik & Diterima & Sesuai \\
\hline 22 & 1703050 & SMA & - & 0 tahun & B & - & - & - & Ditolak & Sesuai \\
\hline 23 & 1703057 & S1 & Pertanian & 1 tahun & B & Cukup & Baik & Baik & Ditolak & Sesuai \\
\hline 24 & 1703055 & SMA & - & 3 tahun & B & - & - & - & Ditolak & Sesuai \\
\hline 25 & 1703218 & SMA & - & 0 tahun & A & Baik & Baik & Kurang & Ditolak & Sesuai \\
\hline 26 & 1703211 & SMA & - & 5 tahun & B & - & - & - & Ditolak & Sesuai \\
\hline 27 & 1703145 & SMA & - & 0 tahun & $\mathrm{C}$ & - & - & - & Ditolak & Sesuai \\
\hline 28 & 1703290 & SMA & - & 0 tahun & $\mathrm{C}$ & - & - & - & Ditolak & Sesuai \\
\hline 29 & 1703187 & S1 & Manajemen & 2 tahun & B & Baik & Baik & Baik & Diterima & Sesuai \\
\hline 30 & 1703058 & SMA & - & 0 tahun & $\mathrm{C}$ & - & - & - & Ditolak & Sesuai \\
\hline 31 & 1703286 & SMA & - & 3 tahun & $\mathrm{C}$ & - & - & - & Ditolak & Sesuai \\
\hline 32 & 1703231 & S1 & Adm.Pend. & 1 tahun & A & Baik & Baik & Cukup & Diterima & $\begin{array}{l}\text { Tidak } \\
\text { Sesuai }\end{array}$ \\
\hline 33 & 1703058 & D3 & Akuntansi & 2 tahun & B & Baik & Cukup & Baik & Diterima & Sesuai \\
\hline 34 & 1703151 & SMA & - & 4 tahun & B & Baik & Kurang & Cukup & Ditolak & Sesuai \\
\hline 35 & 1703180 & SMA & - & 2 tahun & $\mathrm{C}$ & - & - & - & Ditolak & Sesuai \\
\hline
\end{tabular}

\section{Kesimpulan}

Dari pengumpulan data-data dan pengujian-pengujian yang telah dilakukkan. Dengan hasil uji tingkat akurasi sebelum menggunakan metode, tingkat akurasinya hanya sebesar $68 \%$ (persen). Sedangkan setelah diterapkannya metode, tingkat akurasinya menjadi $94 \%$ (persen).

\section{Saran}

Saran untuk penelitian ini adalah dapat dilakukan penambahan jumlah kriteria dan sub kriteria yang digunakan. Serta
Maka dapat ditarik kesimpulan bahwa aplikasi penerapan metode AHP pada proses seleksi karyawan bagian keuangan di PT. Bumi Hutan Semesta ini dapat digunakan dan diimplementasikan sebagai langkah penyelesaian masalah subjektifitas yang ada pada sistem seleksi selama ini. proses seleksi karyawan ini juga bisa menggunakan metode lainnya dan penelitian ini dapat dipakai sebagai tolak ukur.

\section{DAFTAR PUSTAKA}

Fatta, H. A. (2009). Pengembangan Sistem Pendukung Keputusan untuk Penilaian Ujian Tugas Skripsi. 2.

Hariandja, M. T. (2007). MANAJEMEN SUMER DAYA MANUSIA Pengadaan, Pengembangan, Pengkompensasian, dan Peningkatan Produktivitas Pegawai.

Kusrini. (2007). Konsep dan Aplikasi SISTEM PENDUKUNG KEPUTUSAN. Yogyakarta: ANDI. 
Latifah, S. (2005). Prinsip-prinsip Dasar AHP. 2.

Maharani, R. H., Syukur, A., \& Catur, T. (2010). Penerapan Metode AHP dalam Penerimaan Karyawan Pada PT. Pasir Besi Indonesia. Jurnal Teknologi Informasi, Vol. 6, 102.

Marimin. (2008). Teknik \& Aplikasi Pengambilan Keputusan Kriteria Majemuk. Jakarta: Grasindo.

Mora, M. (2009). Analisis Sensitivitas dan Pengaruhnya Terhadap Urutan Prioritas Dalam Metode AHP. 21.

Napitupulu, I. J. (2010). Pembangunan Berkelanjutan Peran dan Kontribusi Emil Salim. Jakarta: Gramedia.

Parapat, D. J. (2009). Model Penentuan Prioritas Dalam AHP Melalui Koefisien Korelasi. 19.

Rochmasari, L., Suprapedi, \& Subagyo, H. (2010). Penentuan Prioritas Usulan Sertifikasi Guru Dengan Metode AHP. Jurnal Tenologi Informasi , 6, 6.

Sensuse, Sari, F. R., \& Indra, D. (2010). Penerapan Process Dalam Sistem Penunjang Keputusan Untuk Pemilihan Asuransi. 1.

Supriyono. (2007). Sistem Pemilihan Pejabat Struktural dengan Metode AHP.

Wardhani, Y. F., \& Viatrie, D. I. (2006). Latihan Soal-soal Psikotes untuk Pelamar Kerja. Depok: Kawan Pustaka.

Wibisono, D. (2008). Riset Bisnis Panduan bagi Praktisi dan Akademisi. Jakarta: Gramedia. 